\title{
Synthesis and Characterization of Polyacrylamide Crosslinked Copolymer for Enhanced Oil Recovery and Rock Wettability Alteration
}

\author{
Abdelaziz El Hoshoudy ${ }^{1,}$, , Saad Desouky ${ }^{1}$, Ahmed Al-sabagh ${ }^{1}$, Mohammed El-kady ${ }^{2}$, \\ Mohammed Betiha ${ }^{1}$, Sawsan Mahmoud ${ }^{1}$ \\ ${ }^{1}$ Egyptian Petroleum Research Institute, Naser City, Cairo, Egypt \\ ${ }^{2}$ Department of Chemistry, Ainshams University, Faculty of Science, Cairo, Egypt
}

Email address:

azizchemist@yahoo.com (A. N. El-Hoshoudy)

To cite this article:

Abdelaziz El hoshoudy, Saad Desouky, Ahmed Al sabagh, Mohammed El kady, Mohammed Betiha, Sawsan Mahmoud. Synthesis and Characterization of Polyacrylamide Crosslinked Copolymer for Enhanced Oil Recovery and Rock Wettability Alteration. International Journal of Oil, Gas and Coal Engineering. Vol. 3, No. 4, 2015, pp. 47-59. doi: 10.11648/j.ogce.20150304.11

\begin{abstract}
Recently enhanced oil recovery (EOR) technology is getting more attention by many countries since energy crises are getting worse and frightened. To improve oil recovery several techniques had been employed, one of them is wettability alteration by chemical agents flooding. In this research a novel copolymer (Acrylamide-4-Dodecyl-benzenesulfonate-1vinylimidazol-3-ium-Divinyl sulfone) prepared by free radical emulsion polymerization of acrylamide (AM), 4-Dodecylbenzenesulfonate-1-vinylimidazol-3-ium (DBSV) as amphoteric surfmer and divinyl sulfone (DVS) as hydrophobic crosslinker moiety had been prepared and characterized. Chemical structure of the prepared copolymer was proven through different techniques such as Fourier transform infrared spectroscopy (FTIR), nuclear magnetic spectroscopy (1H\&13C-NMR), scanning electron microscope (SEM), high resolution transmission electron microscope (HRTEM), while particle size and particle size distribution were characterized by dynamic light scattering (DLS) and thermal properties characterized by thermal gravimetric analysis (TGA) and differential scanning calorimetry (DSC). Wettability alteration was evaluated by contact angle measurements through static sessile drop method, where the results indicate the novel copolymer ability for altering wettability of sandstone rock from oil-wet to water wet even at harsh reservoir conditions, so enhance oil recovery factor.
\end{abstract}

Keywords: Polymeric Surfmers, Hydrophobically Associated Polyacrylamide, Free Radical Emulsion Polymerization, Wettability Alteration, Enhanced Oil Recovery

\section{Introduction}

Petroleum products are crucial to the global economy today due to increasing energy demand approximately $1.5 \%$ per year [1] associated with population growth and improving life styles, so there is a dire need to produce more unrecoverable crude oil through different enhanced oil recovery (EOR) techniques. To increase the oil recovery efficiency in oil-wet reservoirs (unswept regions), different techniques have to be pursued [2]; such as 1) improving volumetric sweeping efficiency by adjusting the oil/water mobility ratio through polymers flooding agents which increase displacing fluid viscosity in order to modify the viscous forces being applied to drive oil out of the pores [3], thus increasing produced crude oil amount, 2) altering the wettability of porous reservoir rock surfaces to more water wet [4] (i.e. by letting the value of contact angle $\theta \leq 900$ ). The success of wettability alteration is seen as the increment in percentage of recovered oil, depending on natural wettability [5], 3) increase the oil displacement effectiveness by overcoming the capillary barrier through viscous and gravitational forces, so water can invade the rock matrix (i.e. modifying permeability) and displace the oil through surfactants flooding to lower the oil-water interfacial tension (IFT), to ultra low values $\sim 10-3$ dyne/cm [6]. Polymer flooding through hydrophobically associated polyacrylamide polymers (HAPAM) have attracted much attention in enhanced oil recovery $[7,8]$ because of their unique structures 
and properties, including their thickening properties, shear thinning, anti polyelectrolyte behavior as mobility control agents and rheology modifiers [9]. These polymers synthesized by free radical emulsion polymerization process through grafting or incorporating hydrophobic chain crosslinking segments onto their hydrophilic main chain $[10,11]$ or by copolymerization of hydrophilic and hydrophobic monomers [12].

Polymeric surfactants (surface-active monomers) are functional surfactants, have amphiphilic structure [13], and contain polymerizable vinyl double bonds [14] in their molecular architecture either at the head (H-type) or the tail (T-type) resulting in novel physicochemical properties distinct from conventional surfactants [15]. When these hydrophilic surfmers are adopted to prepare HAPAM, homogeneous phase copolymerization of hydrophilic surfmers and acrylamide in aqueous solution can be carried out because of their solubility in water, and those drawbacks caused by the addition of small molecule surfactants can be avoided completely.

Wettability of reservoir rock is a surface phenomenon controlling the location, flow, distribution of the fluids in a reservoir [16] and affects saturation and enhanced oil recovery processes $[17,18]$. Wettability is classically defined using the concept of contact angle which arise at the intersection between two immiscible fluid phases and the rock surface. Since, there is a Conesus in petroleum engineering that preferentially water-wet cores flood more efficiently than oil-wet cores; since, more oil is recovered from water-wet cores in the early flooding stages than from oil-wet cores [19], so the authors reported about synthesis of a novel surfmers (H-type) by the reaction of a 1- vinyl imidazole as a polymeric moiety containing double bond and 4- Dodecyl benzene sulfonic acid surfactant, then poly(4Dodecyl-benzenesulfonate3-[5-(butane-2-sulfonyl)-3-

carbamoyl-1-methyl-heptyl]imidazol-3-ium) crosslinked copolymer as a novel candidate from hydrophobically associating polyacrylamide (HAPAM) class prepared by free radical emulsion polymerization of acrylamide (AM) monomer, divinyl sulfone as hydrophobic crosslinked moiety and surfmers, to chemically anchor a surfmer and hydrophobic crosslinker moiety onto the hydrophilic back bone of acrylamide chain, then evaluating the prepared copolymer ability to alter wettability of sandstone rock from oil-wet to water-wet. To the best of our knowledge, the novel copolymer hadn't been previously reported in enhanced oil recovery applications as a wettability modifying agents.

\section{Experimental}

\subsection{Materials}

4- Dodecyl benzene sulfonic acid (DBSH; mixture of isomers; $\geq 95 \%$ ), 1-vinylimidazole ( $\geq 99 \%)$, ethyl acetate (CH3COOC2H5; $\geq 99.5 \%$ ), acrylamide (AM; 99\% was twice recrystallized from acetone, dried under vacuum, and stored in the dark at $4 \mathrm{oC}$ until required, potassium persulfate "KPS"
(K2S2O8; $\geq 99 \%$ ), divinyl sulfone (DVS; $\geq 97 \%$ ), acetone (CH3COCH $3 ; \geq 97 \%$ ), methanol $(\mathrm{CH} 3 \mathrm{OH} \geq 97 \%)$, potassium bromate $(\mathrm{KBrO} 3-\mathrm{KBr}$; $\geq 99.8 \%)$, potassium iodide (KI; $\geq 99.5 \%$ ), sodium thiosulfate $(\mathrm{Na} 2 \mathrm{~S} 2 \mathrm{O} 3 ; \geq 98 \%$ ). All reagents and materials of the best grade available were used without additional purification, supplied from Sigma-Aldrich Chemie $\mathrm{GmbH}$. All aqueous solutions were prepared using deionized or Milli-Q water.

\subsection{Synthesis}

\subsubsection{Preparation of Surfmer (4-Dodecyl- benzenesulfonate-1-vinylimidazol-3-ium; DBSV) $\left(\mathrm{C}_{23} \mathrm{H}_{36} \mathrm{~N}_{2} \mathrm{O}_{3} \mathrm{~S}\right)(\mathrm{Mol}$. wt. $=420.609)$}

The addition reaction was carried out in a $250 \mathrm{ml}$ threenecked Erlenmeyer flask equipped with reflux condenser, mechanical stirrer, and nitrogen inlet/outlet. To a stirred solution of (34.68 g, $0.106 \mathrm{~mol})$ of 4-Dodecyl benzene sulfonic acid in ethyl acetate $(150 \mathrm{ml})$, under inert nitrogen atmosphere, 1-vinylimidazole (10 g, $0.106 \mathrm{~mol})$ was added drop wise under vigorous stirring in ice bath. The solution was maintained at $0^{\circ} \mathrm{C}$ for $2 \mathrm{~h}$ and then stirred for $12 \mathrm{~h}$ at $45^{\circ} \mathrm{C}$. The white product was precipitated by lowering temperature to $-16^{\circ} \mathrm{C}$ and recrystallized through re-dissolving in $50 \mathrm{ml}$ ethyl acetate and cooling. The yield was about $73 \%$.

\subsubsection{Preparation of HAPAM Copolymer "Poly(4-Dodecyl- benzenesulfonate3-[5-(butane-2-sulfonyl)-3- carbamoyl-1-methyl-heptyl]imidazol-3-ium)"}

An aqueous solution of acrylamide in distilled water was gently bubbled with nitrogen gas for $30 \mathrm{~min}$ to remove dissolved oxygen (free radical scavenger). The emulsion polymerization was carried out in a jacketed autoclave equipped with mechanical stirrer, automated temperature controlling unit, and nitrogen inlet/outlet. The designated amounts of acrylamide monomer, hydrophobic divinyl sulfone crosslinker and surfmer were added into the mixture, stirred vigoursly until a clear solution was obtained. The reaction was started by injecting potassium persulfate (K2S2O8) as an initiator at the desired reaction temperature, and the reaction mixture was stirred for 12 hours under a nitrogen purge for (1-1.5 h) to ensure the complete removal of trapped air due to strong foaming arising from the presence of surfmer in the solution. Concentrations of initiator, monomer, cross linker, surfmer and reaction conditions are reported in Table 1. A sample of polymerized emulsion was withdrawn at different polymerization intervals to determine conversion $\%$.

Table 1. Reactants concentration and reaction conditions.

\begin{tabular}{|c|c|c|c|c|c|c|c|}
\hline $\mathbf{A}$ & B & $\mathrm{C}$ & D & $\mathbf{E}$ & $\mathbf{G}$ & $\mathbf{H}$ & I \\
\hline 1.69 & $3.38 * 10^{-2}$ & $6.07 * 10^{-3}$ & $1.14 * 10^{-2}$ & 5.4 & 12 & 260 & 1908.07 \\
\hline $\begin{array}{l}\text { A; } \\
\text { Conc } \\
\text { Cross } \\
\text { value } \\
\text { Visco }\end{array}$ & $\begin{array}{l}\text { onomer } \\
\text { tration, M } \\
\text { linker (DV } \\
\text { G; Reactic } \\
\text { ty, mPa.s }\end{array}$ & $\begin{array}{l}\text { crylamide) } \\
\text { L-1. C; I } \\
\text { Concentra } \\
\text { Time, Ho }\end{array}$ & $\begin{array}{l}\text { Concentra } \\
\text { itiator (KF } \\
\text { ion, Mol L } \\
\text { rs. H; De }\end{array}$ & $\begin{array}{l}\text { n, Mol } \\
\text { Concentr } \\
\text { E; Temp } \\
\text { hized Wate }\end{array}$ & $\begin{array}{l}\text { L-1. } \\
\text { ation } \\
\text { eratu }\end{array}$ & $\begin{array}{l}\mathrm{B} ; \\
\mathrm{Mol} \\
\mathrm{re}, \mathrm{oC}\end{array}$ & $\begin{array}{l}\text { Surfmer } \\
\text { L-1. D; } \\
\text { F. F; PH- } \\
\text { Apparent }\end{array}$ \\
\hline
\end{tabular}


At the end of the reaction, the viscous polymer gel was obtained. After cooling the final reaction mixture, the viscous polymer gel was precipitated by mixing it with an excess of acetone, re-dissolved in water and re-precipitated in acetone, then subjected to Soxhlet extraction with methanol for $24 \mathrm{~h}$ in order to remove unreacted monomers until a white block solid obtained. Finally, the solid copolymer was further crushed and vacuum dried at $60^{\circ} \mathrm{C}$ for 24 hours, and then stored in a desiccator. As a reference, polyacrylamides homopolymers were synthesized and purified under identical conditions.

The overall monomer conversion could be obtained by determining the residual contents of monomers containing polymeric double bond with bromating method [20] as follow; at different intervals about $4.0 \mathrm{~g}$ of as synthesized copolymer was withdrawn and a small amount of hydroquinone was mixed with each drawn sample to terminate the polymerization. The sample weighed out in a weighing bottle, and then $100 \mathrm{ml}$ of deionized water was added. After stirring adequately, the sample solution could be obtained. Excessive $\mathrm{KBrO}_{3}-\mathrm{KBr}$ was added into the sample solution. In the presence of $\mathrm{H}^{+}, \mathrm{KBrO}_{3}$ reacted with $\mathrm{KBr}$ to produce $\mathrm{Br}_{2}$, and then $\mathrm{Br}_{2}$ could react with residual monomers in the sample solution for addition reaction. Excessive KI was used to react with the residual $\mathrm{Br}_{2}$, and $\mathrm{I}_{2}$ was formed from the reaction mixture. By titrating $\mathrm{I}_{2}$ with the standard solution of $\mathrm{Na}_{2} \mathrm{~S}_{2} \mathrm{O}_{3}$ and calculating the consumption of $\mathrm{Na}_{2} \mathrm{~S}_{2} \mathrm{O}_{3}$, the total residual contents of monomers could be determined by means of the interrelationship of these ingredients [21]. In addition to previous method, monomer conversion was proved by gravimetric precipitation technique. A definite weight of as synthesized copolymer was withdrawn and precipitated in acetone at interval time of $(2,4,6,8,10,12,14$ hours), and reweighted after vaccum drying. The converted monomer was calculated by subtracting weight after drying from theoretical weight of monomer in definite solution. All titration experiments were repeated 3 times for accuracy.

\subsection{Characterization and Equipments}

FTIR spectrometric analysis carried on American FTS3000 infrared spectrometer in the optical range 600-4000 $\mathrm{cm}^{-1}$ by the averaging of 32 scans at a resolution of $4 \mathrm{~cm}^{-1}$ with $\mathrm{KBr}$ pellets. Simultaneous thermal analysis (TGA-DSC) was measured on TA-instrument SDT Q600 V20.5 Build 15 thermoanalyzer (TGA) under $\mathrm{N}_{2}$ atmosphere at $50 \mathrm{ml} / \mathrm{min}$ in order to exclude the probability of formation of non-volatile oxidative degradation products that causes some calculations uncertainties, where the samples were thermally scanned from room temperature to $600^{\circ} \mathrm{C}$ at scanning rate of $20^{\circ} \mathrm{C} /$ min. The latex morphology was observed on Japanese JEOL high resolution transmission electron microscope (JEM$2100 \mathrm{~F}$ type) under voltage of $200 \mathrm{kV}$. The magnification of transmission electron micrograph (HRTEM) was fixed at 100,000 times. The samples were diluted up to 20 times, and then dispersed by a Julabo Labortechnik GMBH D-733 Seelbach (Germany) ultrasound bath with frequency of 5
$\mathrm{kHz}$ in distilled water as a solvent and dropped on a copper grid for TEM analysis. To observe the surface morphology of the samples, a Quanta 450-scanning electron microscopy (SEM) instrument was used at resolution of $10 \mu \mathrm{m}$. Analysis was achieved at an acceleration voltage of $20 \mathrm{kV}$ and a pressure of $120-500 \mathrm{~Pa}$ in the sample chamber, where polymer composite were dissolved in the deionized water at a concentration of $2000 \mathrm{mgL}^{-1}$. ${ }^{1} \mathrm{H}-\mathrm{NMR}$ and ${ }^{13} \mathrm{C} \mathrm{NMR}$ analyses were measured with a Bruker EMX $400 \mathrm{MHz}$ NMR spectrometer (Billerica, MA, USA). The spectrum was recorded after accumulating 32 scans, using $\mathrm{CDCl}_{3}$ and $\mathrm{D}_{2} \mathrm{O}$ as solvents and tetramethylsilane (TMS) as internal standard. The particle size distribution and zeta potential of HAPAM latexes was determined by (Zetasizer ver. 6.32, Serial Number : MAL1071664 Nano Series, Nano-ZS, Malvern Instruments, UK)-dynamic light scattering (DLS) equipped with a cuvette rotation/translation unit (CRTU) and a He-Ne laser at scattering angle $90^{\circ}$ and $25^{\circ} \mathrm{C}$. The acquisition time for each run was 30 seconds. The molecular weight was measured by gel permeation chromatography (GPC) using a Waters 600E system controller equipped with a Waters 610 Fluid Unit pump and a Waters 410 differential refractometer as detector. The GPC sample was prepared by dissolving the purified polymer sample into deionized water and filtering the obtained solution by a teflon membrane filter (pore size $0.45 \mathrm{~mm}$ ). Moreover, intrinsic viscosity of the copolymers were measured in $0.5 \mathrm{molL}^{-1} \mathrm{NaCl}$ aqueous solutions at a constant temperature of $\left(25.0 \pm 0.1^{\circ} \mathrm{C}\right)$ with a Cannon-Fenske viscometer [22] via the dilution extrapolation method.

\section{Results and Discussions}

\subsection{Spectroscopic Analysis of Surfmer}

IR spectra of 1-vinyl imidazole, 4-Dodecyl benzene sulfonic acid and the prepared surfmer (4-Dodecylbenzenesulfonate-1-vinylimidazol-3-ium) with their characteristic peaks are shown in Fig. 1.

1 -vinyl imidazole shows peaks at $3113 \& 1548 \mathrm{~cm}^{-1}$ which assigned to $(\mathrm{C}-\mathrm{H})$ and $(\mathrm{C}=\mathrm{C})$ stretching vibration in vinyl group $\left(-\mathrm{CH}=\mathrm{CH}_{2}\right)$ respectively, while the peaks at $1005 \&$ $650 \mathrm{~cm}^{-1}$ correspond to bending of $(\mathrm{C}-\mathrm{H})$ bond. The peaks observed at $1649 \& 1230 \mathrm{~cm}^{-1}$ correspond to stretching vibration of $(\mathrm{C}=\mathrm{N})$ and $(\mathrm{C}-\mathrm{N})$ bonds respectively. 4-Dodecyl benzene sulfonic acid shows absorption peaks at $3700 \mathrm{~cm}^{-1}$ is assignable to $(\mathrm{O}-\mathrm{H})$ stretching vibration while, peaks observed at $2958 \& 2855 \mathrm{~cm}^{-1}$ correspond to (C-H) stretching vibration in benzene ring and aliphatic chain respectively. The peak at $1131 \mathrm{~cm}^{-1}$ is assignable to stretching vibration of $(\mathrm{S}=\mathrm{O})$ in sulfonic acid. The peak at $833 \mathrm{~cm}^{-1}$ corresponds to $(\mathrm{C}-\mathrm{H})$ bending in disubstituted benzene ring. 4-Dodecyl benzene sulfonate-1-vinylimidazol3-ium shows observed peaks at $3126,1660 \& 834 \mathrm{~cm}^{-1}$ which correspond to stretching, bending and wagging vibration motion of $(\mathrm{N}-\mathrm{H})$ respectively. Moreover observed peak at $1127 \mathrm{~cm}^{-1}$ which assigned to stretching vibration of $(\mathrm{S}=\mathrm{O})$ in sulfonate salts confirms that quaternization on 
nitrogen atom in imidazole ring occur successfully.

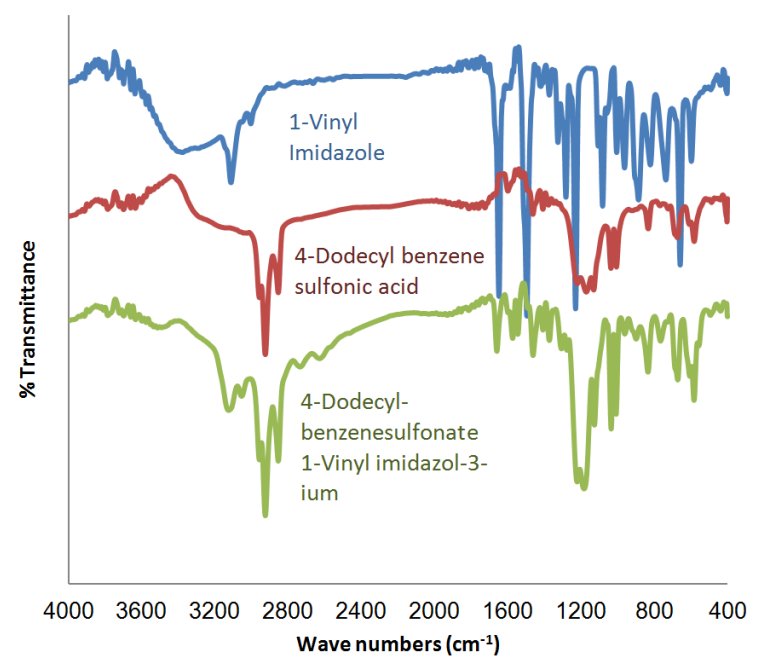

Fig. 1. FTIR spectra of 1-vinyl imidazole, surfactant and surfmer.

Since IR spectrum alone does not give complete information concerning chemical structure. So, proton ${ }^{1} \mathrm{H}$ $\mathrm{NMR}$ and carbon ${ }^{13} \mathrm{C}$-NMR analyses are shown in Fig. 2 and 3 respectively, with their chemical shifts.

${ }^{1} \mathrm{H}-\mathrm{NMR}\left(400 \mathrm{MHz}, \mathrm{CDCl}_{3}, 25^{\circ} \mathrm{C}\right)$ of 1-vinylimidazole; show chemical shifts at $\delta(\mathrm{ppm})=4.66(\mathrm{dd}, 1 \mathrm{H}$, trans$\left.\mathrm{CHCH}_{2}\right), 4.9$ (dd, $1 \mathrm{H}$, cis- $\left.\mathrm{CHCH}_{2}\right), 6.3(\mathrm{dd}, 1 \mathrm{H},-\mathrm{CHCH} 2)$, $6.6(\mathrm{~s}, 1 \mathrm{H}, \mathrm{N}(1) \mathrm{CHCH}-), 7.2$ (s, 1H, -NCHN-). ${ }^{1} \mathrm{H}-\mathrm{NMR}$ (400 $\mathrm{MHz}, \mathrm{CDCl}_{3}, 25^{\circ} \mathrm{C}$ ) of 4-Dodecyl benzene sulfonic acid; show chemical shifts at $\delta(\mathrm{ppm})=0.877\left(\mathrm{t}, 3 \mathrm{H}, \mathrm{CH}_{3} \mathrm{CH}_{2}\right)$, 1.089- 1.254 (t, 20H, $\left.\mathrm{CH}_{3} \mathrm{CH}_{2} \mathrm{CH}_{2} \mathrm{CH}_{2}\right), 2.737$ (t, $2 \mathrm{H}$, $\mathrm{CH} 2 \mathrm{CH} 2-\mathrm{Ph}), 7.387\left(\mathrm{~m}, 2 \mathrm{H}, \mathrm{Ph}-\mathrm{CH}_{2}-\mathrm{CH}_{2}\right), 7.838(\mathrm{~m}, 2 \mathrm{H}$,
Ph-SO $\left.3^{-}\right), 11.47$ (s, $\left.1 \mathrm{H},-\mathrm{SO}_{3}-\mathrm{H}\right) .{ }^{1} \mathrm{H}-\mathrm{NMR}\left(400 \mathrm{MHz}, \mathrm{CDCl}_{3}\right.$, $25^{\circ} \mathrm{C}$ ) of 4-Dodecyl benzenesulfonate-1-vinylimidazol-3-ium; show chemical shifts at $\delta(\mathrm{ppm})=0.656-1.408(\mathrm{~m} \& \mathrm{t}, 25 \mathrm{H}$, $\left.\mathrm{CH} 3\left(\mathrm{CH}_{2}\right) \mathrm{n}\right), 5.01$ (dd, $1 \mathrm{H}$, trans- $\left.\mathrm{CHCH}_{2}\right), 5.57$ (dd, $1 \mathrm{H}$, cis$\left.\mathrm{CHCH}_{2}\right), 5.62$ (dd, 1H, -CHCH2), 7.018 (s, 1H, N(1)CHCH), 7.2 (s, 1H, -NCHN-), 7.694 (m, 4H, Ph), 14.5(S, 1H, - $\mathrm{SO}_{3}-$ $\mathrm{H})$. The presence of peaks at 5.01, 5.57\&5.62 indicate presence of vinyl group after quaternization process, moreover the shift of (-NCHN-) peak from 6.6 to 7.2 indicate presence of positively charged nitrogen atom. The chemical shift of $\left(-\mathrm{SO}_{3}-\mathrm{H}\right)$ in dodecyl benzene sulfonic acid from 11.47 to 14.5 confirms that quaternization process occurs successfully.

${ }^{13} \mathrm{C}$-NMR $\left(400 \mathrm{MHz}, \mathrm{CDCl}_{3}, 25^{\circ} \mathrm{C}\right)$ of 1-vinylimidazole; show chemical shifts at $\delta(\mathrm{ppm})=136.49(1 \mathrm{C}, \mathrm{N}-\mathrm{C}-\mathrm{N})$, $129.59\left(1 \mathrm{C}, \quad \mathrm{N}-\mathrm{CH}=\mathrm{CH}_{2}\right), \quad 116.18 \quad\left(2 \mathrm{C}, \quad \mathrm{N}-\mathrm{C}_{2} \mathrm{H}_{2}-\mathrm{N}\right)$ and $101\left(1 \mathrm{C}, \mathrm{N}-\mathrm{CH}=\mathrm{CH}_{2}\right) \cdot{ }^{13} \mathrm{C}-\mathrm{NMR}\left(400 \mathrm{MHz}, \mathrm{CDCl}_{3}, 25^{\circ} \mathrm{C}\right)$ of 4-Dodecyl benzene sulfonic acid; show chemical shifts at $\delta$ $(\mathrm{ppm})=154.38\left(1 \mathrm{C}-\mathrm{Ph}-\mathrm{SO}_{3}\right), 143.5\left(1 \mathrm{C}, \mathrm{Ph}-\mathrm{CH}_{2}\right), 128-126$ (4C, $-\mathrm{Ph}), 47.9\left(1 \mathrm{C}, \mathrm{Ph}-\mathrm{CH}_{2}-\mathrm{CH} 2\right), 38.8-31.1\left(8 \mathrm{C},-\mathrm{Ph}-\mathrm{CH}_{2}-\right.$ $\left.\mathrm{C}_{8} \mathrm{H}_{16}-\mathrm{CH}_{2}\right), \quad 29.19\left(1 \mathrm{C},-\mathrm{CH}_{2}-\mathrm{CH}_{2}-\mathrm{CH}_{3}\right), \quad 22.48\left(1 \mathrm{C},-\mathrm{CH}_{2}-\right.$ $\mathrm{CH}_{2}-\mathrm{CH}_{3}$ ) and 21.75(1C, $\left.\mathrm{CH}_{3}-\right) .{ }^{13} \mathrm{C}-\mathrm{NMR}\left(400 \mathrm{MHz}, \mathrm{CDCl}_{3}\right.$, $25^{\circ} \mathrm{C}$ ) of 4-Dodecyl benzenesulfonate-1-vinylimidazol-3-ium; show chemical shifts at $\delta(\mathrm{ppm})=150.38\left(1 \mathrm{C}-\mathrm{Ph}-\mathrm{SO}_{3}\right)$, 148.77 (1C, Ph-CH $\left.\mathrm{CH}_{2}\right), 134.60$ (1C, N-C-N), 128.56 (1C, N$\left.\mathrm{CH}=\mathrm{CH}_{2}\right), 127.59-125.46(4 \mathrm{C},-\mathrm{Ph}), 120.98 \& 118.26(2 \mathrm{C}, \mathrm{N}-$ $\left.\mathrm{C}_{2} \mathrm{H}_{2}-\mathrm{N}\right), \quad 101\left(1 \mathrm{C}, \quad \mathrm{N}-\mathrm{CH}=\mathrm{CH}_{2}\right), \quad 47.9\left(1 \mathrm{C}, \quad \mathrm{Ph}-\mathrm{CH}_{2}-\mathrm{CH} 2\right)$, 39.7-31.62(8C, - $\left.\mathrm{Ph}-\mathrm{CH}_{2}-\mathrm{C}_{8} \mathrm{H}_{16}-\mathrm{CH}_{2}\right), 19.11\left(1 \mathrm{C},-\mathrm{CH}_{2}-\mathrm{CH}_{2}-\right.$ $\left.\mathrm{CH}_{3}\right), 22.52\left(1 \mathrm{C},-\mathrm{CH}_{2}-\mathrm{CH}_{2}-\mathrm{CH}_{3}\right)$ and $11.28\left(1 \mathrm{C}, \mathrm{CH}_{3}^{-}\right)$.

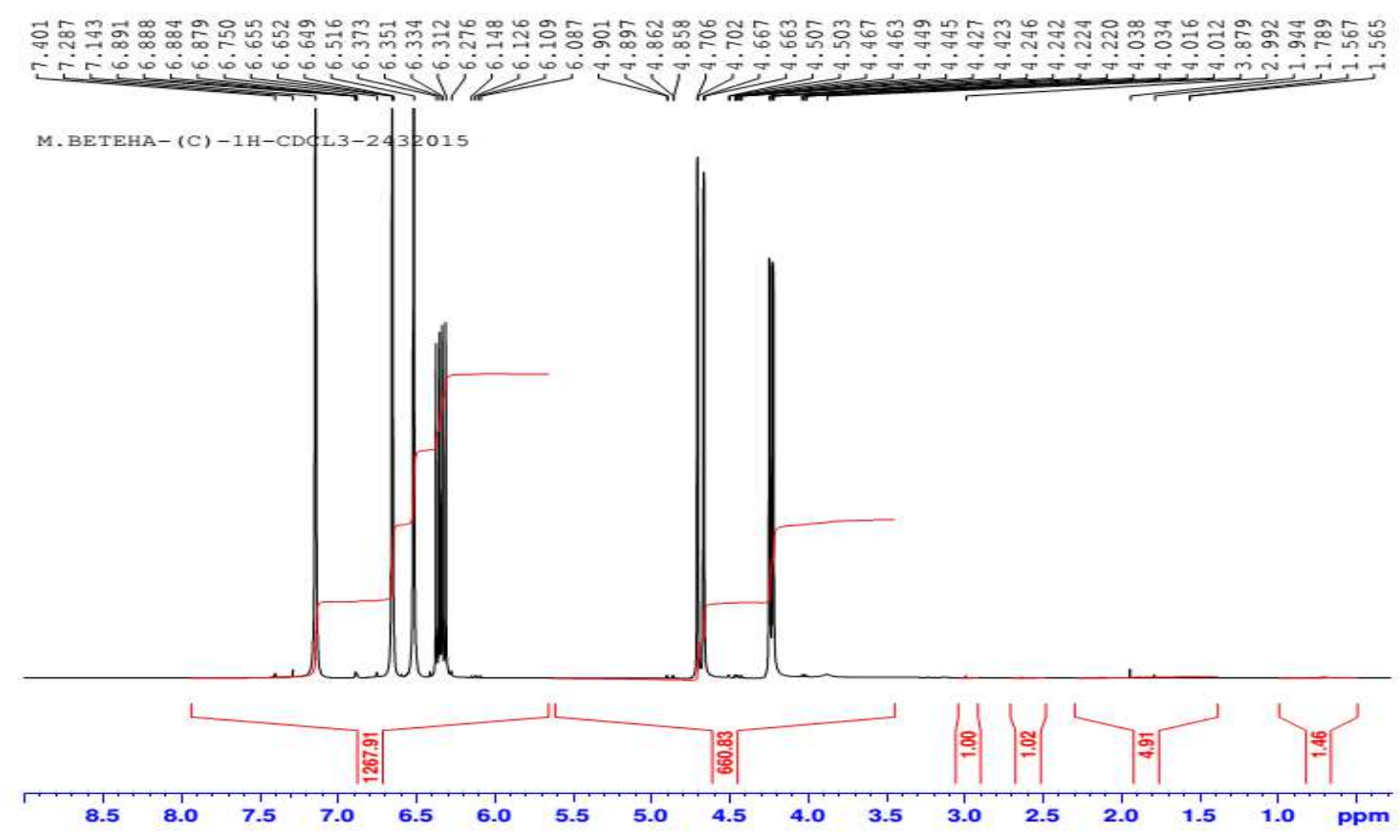

(a) 1-vinyl imidazole. 


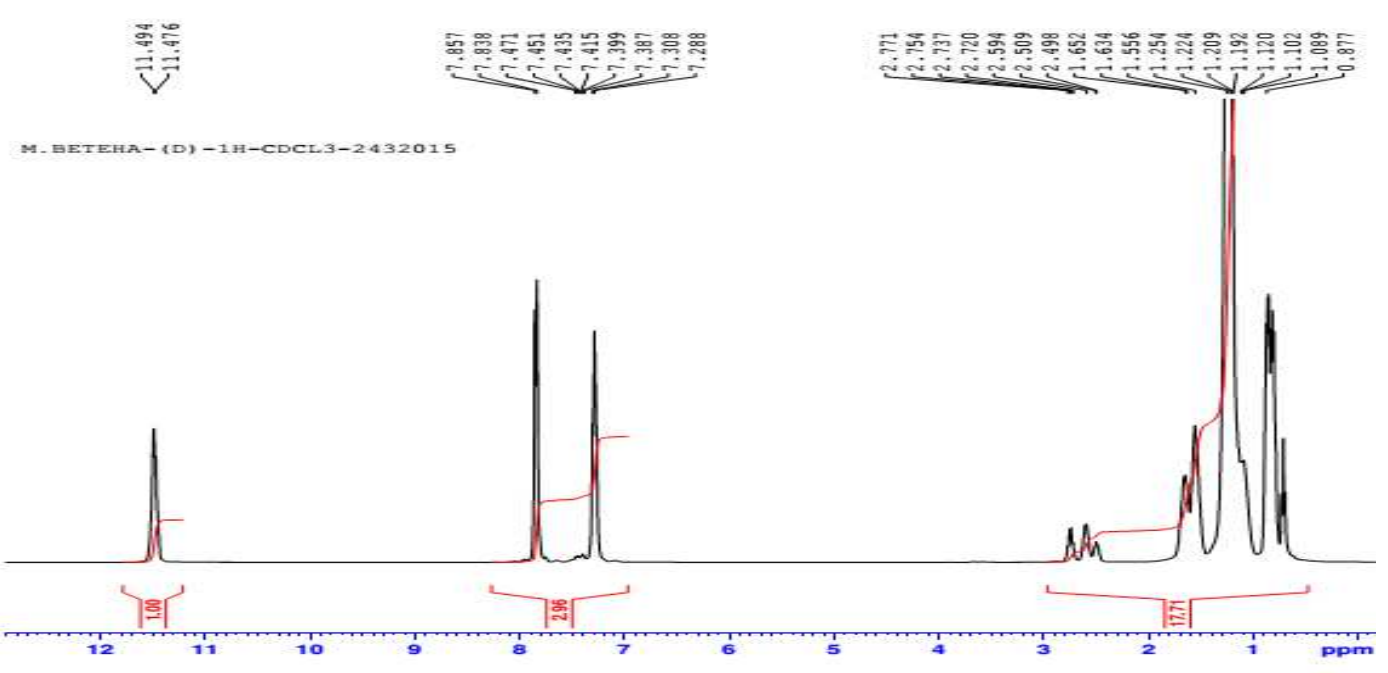

(b) 4-Dodecyl benzene sulfonic acid.

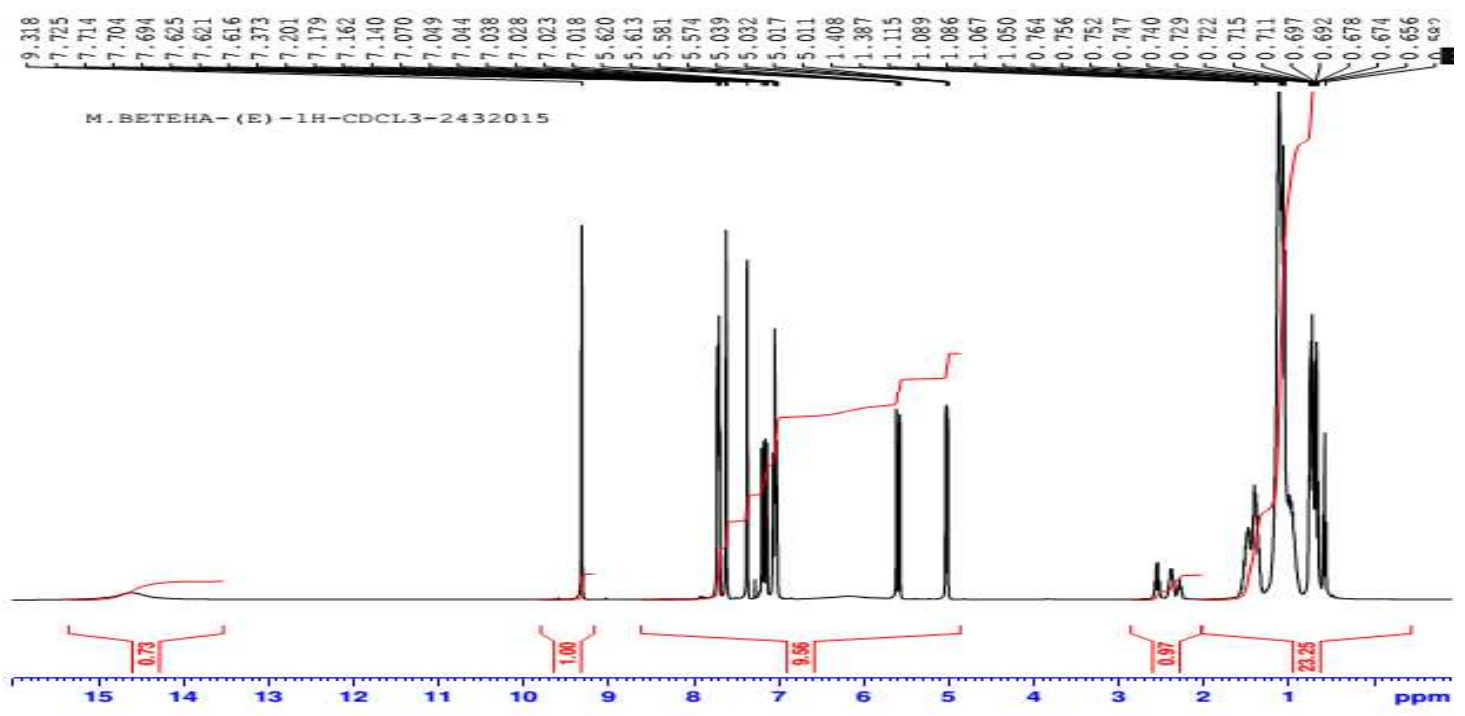

(c) 4-Dodecyl-benzenesulfonate 1-vinylimidazol-3-ium.

Fig. 2. Proton ${ }^{1} H$-NMR spectra of 1-vinyl imidazole, surfactant and surfmer.

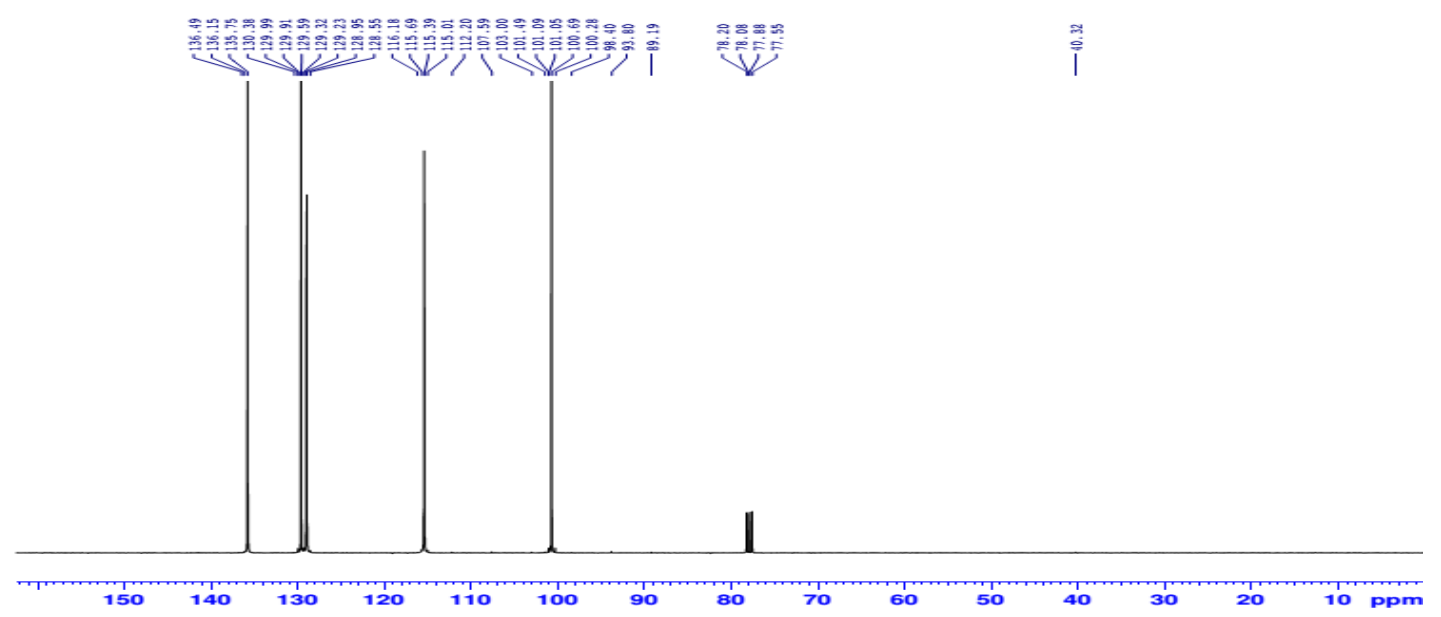

1-vinyl imidazole. 


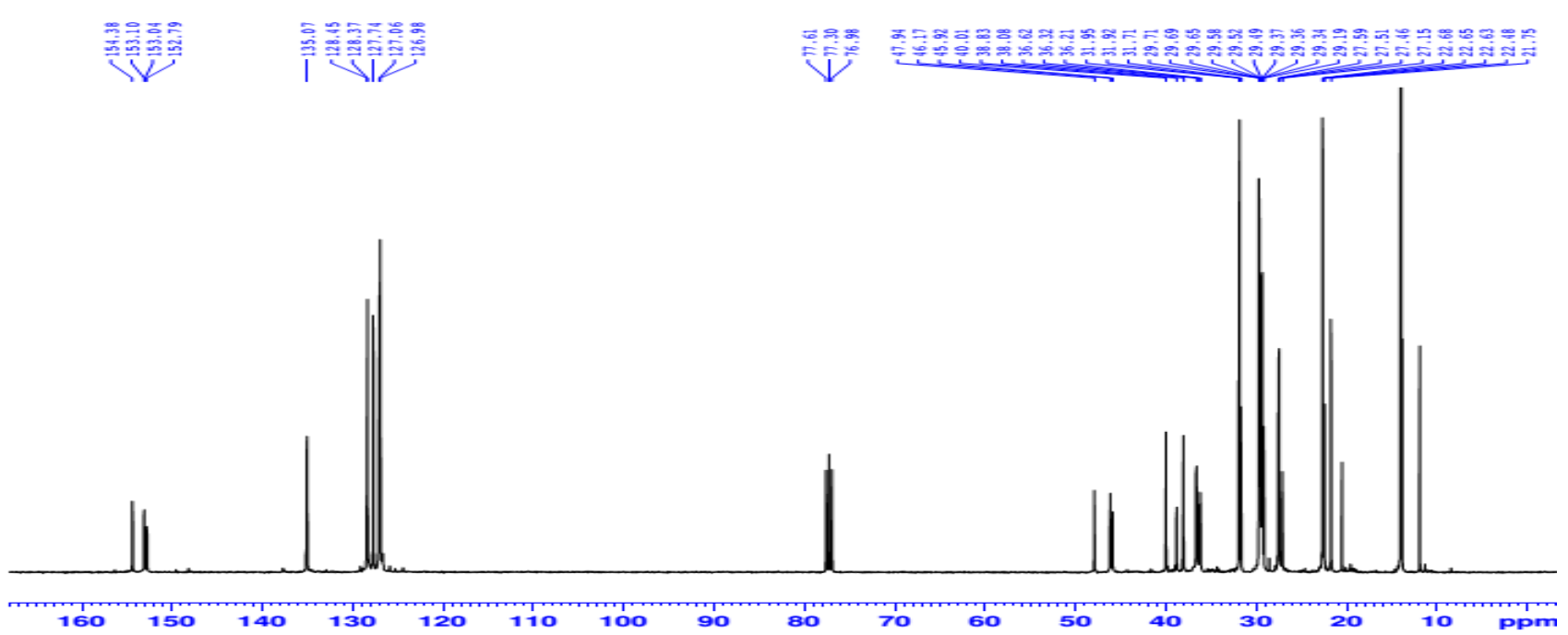

4-Dodecyl benzene sulfonic acid

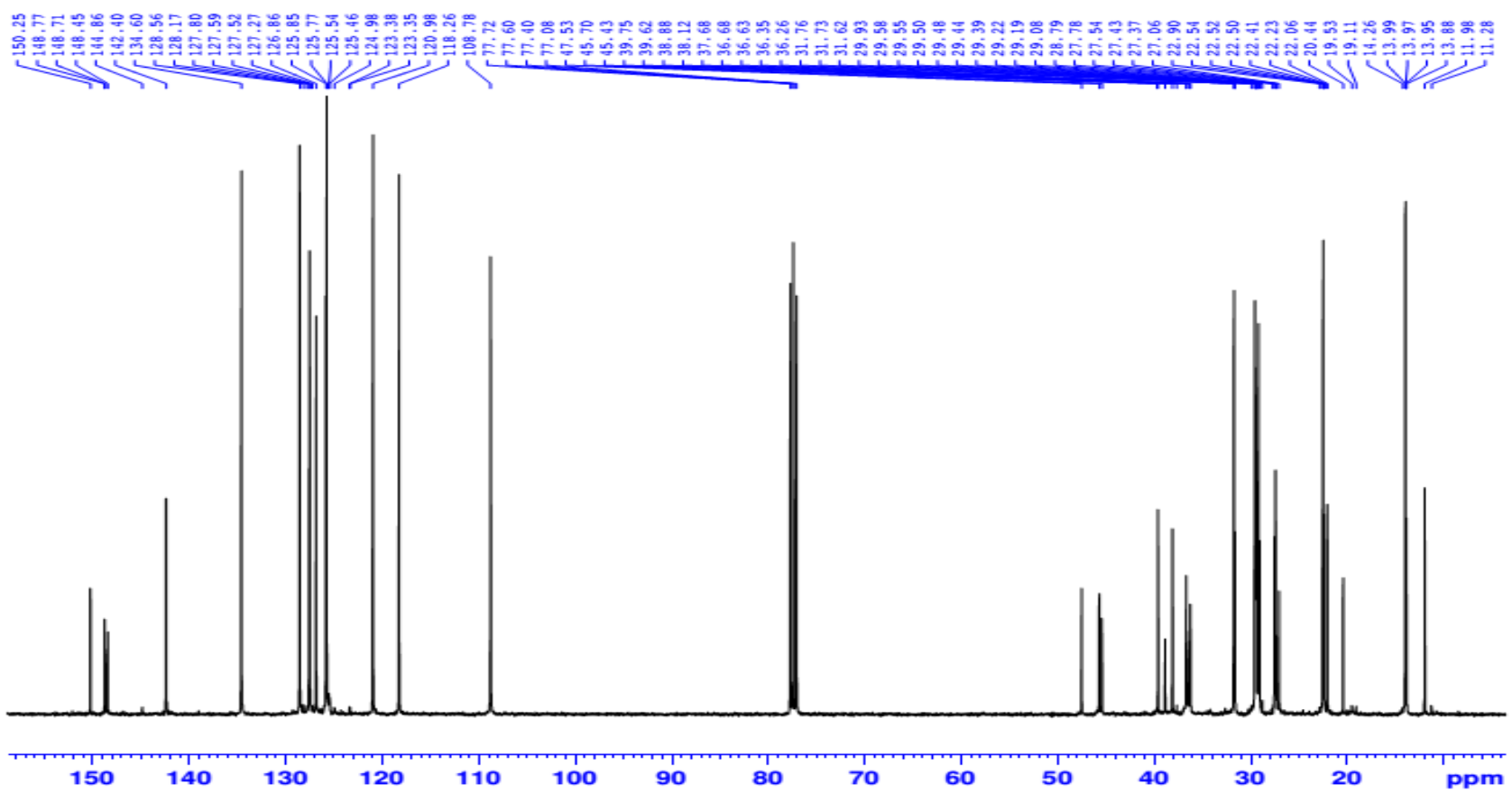

4-Dodecyl-benzenesulfonate 1-vinylimidazol-3-ium.

Fig. 3. Carbon ${ }^{13} \mathrm{C}-\mathrm{NMR}$ spectra of 1-vinyl imidazole, surfactant and surfmer.

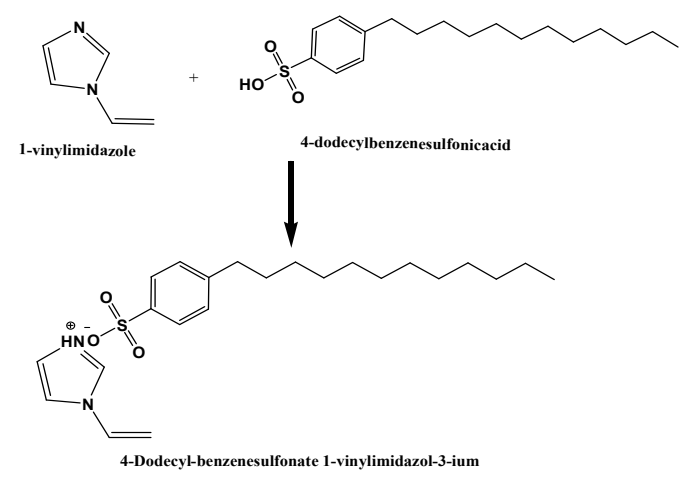

According to the analysis of FTIR, ${ }^{1} \mathrm{H}-\mathrm{NMR}$ and ${ }^{13} \mathrm{C}$ NMR spectra, the proposed chemical structure of surfmer is predicted to be as shown in Fig. 4.

\subsection{Spectroscopic Analysis of HAPAM Copolymer}

Infrared spectroscopy was performed to determine the structure of the copolymer as reported in Fig. 5 with their characteristic peaks as follow:

Fig. 4. Chemical structure of surfmer. 


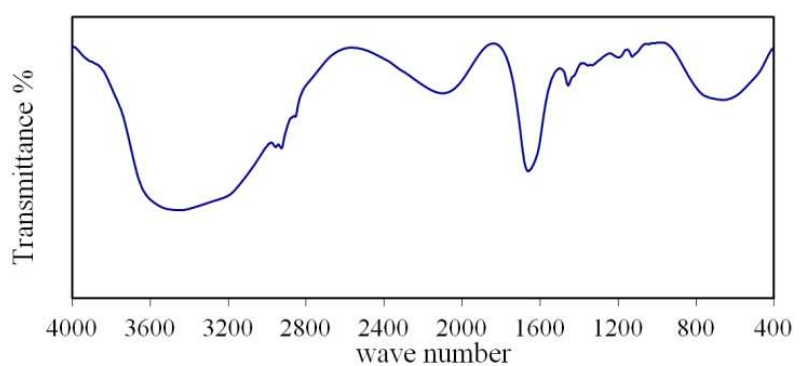

Fig. 5. FTIR of HAPAM copolymer.

HAPAM show strong absorption peaks at 3445-3196 and $1715.62 \mathrm{~cm}^{-1}$; these were attributed to the stretching vibrations of $(\mathrm{N}-\mathrm{H}$ and $\mathrm{C}=\mathrm{O})$ bonds, respectively, in the ($\mathrm{CONH}_{2}$ ) group. The peaks at 2932-2856 $\mathrm{cm}^{-1}$ were assigned to the asymmetric and symmetric stretching vibrations of $(\mathrm{C}$ $\mathrm{H})$ bond in methylene groups respectively [9]. The peak at $1454 \mathrm{~cm}^{-1}$ correspond to bending vibration of methylene from $\left(\mathrm{R}-\mathrm{N}^{+}-\mathrm{R}\right)$, while peak at $1418 \mathrm{~cm}^{-1}$ assigned to bending vibration of methylene in $\left(\mathrm{CH}_{2}-\mathrm{CO}\right)$ group. The absorption peaks at 1323 and 1044 correspond to stretching vibration of $(\mathrm{S}=\mathrm{O})$ in sulfones; this indicated that the divinyl sulfone was successfully introduced into the macromolecule chain. Moreover, peaks at1193 and $622 \mathrm{~cm}^{-1}$ correspond to stretching vibration of $(\mathrm{C}-\mathrm{C})$ and rocking of $\mathrm{CH}_{2}$ - group respectively. The stretching vibration of $(\mathrm{C}=\mathrm{C})$ disappeared within the range of $1600-1680 \mathrm{~cm}^{-1}$. Thus, we can conclude that the acrylamide monomer copolymerized with divinyl sulfone and surfmer in presence of KPS as water soluble initiator to form the proposed structures.

${ }^{1} \mathrm{H}-\mathrm{NMR}\left(400 \mathrm{MHz}, \mathrm{D}_{2} \mathrm{O}, 25^{\circ} \mathrm{C}\right)$ of HAPAM spectra is shown in Fig. 6 with its chemical shifts as follow; chemical shift signal at $\delta=4.70 \mathrm{ppm}$ can be ascribed as the $\left(\mathrm{NH}_{2}\right)$ of the acrylamide chains. The signals at about $3.59 \mathrm{ppm}$ can be assigned to $\left(-\mathrm{CH}_{2}-\mathrm{Ph}-\right)$ and peaks at around 2.64 and $1.64 \mathrm{ppm}$ represent the $\left(-\mathrm{CH}_{2}\right)$ and $(-\mathrm{CH})$ of the HAPAM respectively. The peaks from 1.26 to $1.08 \mathrm{ppm}$ can be assigned to $\left(-\mathrm{CH}_{2}\right)$ and $\left(-\mathrm{CH}_{3}\right)$ of 4-Dodecyl benzene sulfonate-1-vinylimidazol3-ium. Accordingly, the results confirmed that the copolymer was successfully synthesized due to the absence of characteristic band $\left(-\mathrm{CH}_{2}=\mathrm{CH}-\right)$ of acrylamide group and presence of new peaks at 2.64 and $1.64 \mathrm{ppm}$.

According to the analysis of FTIR, ${ }^{1} \mathrm{H}-\mathrm{NMR}$, the proposed chemical structure of HAPAM copolymer is predicted to be as shown in Fig. 7.

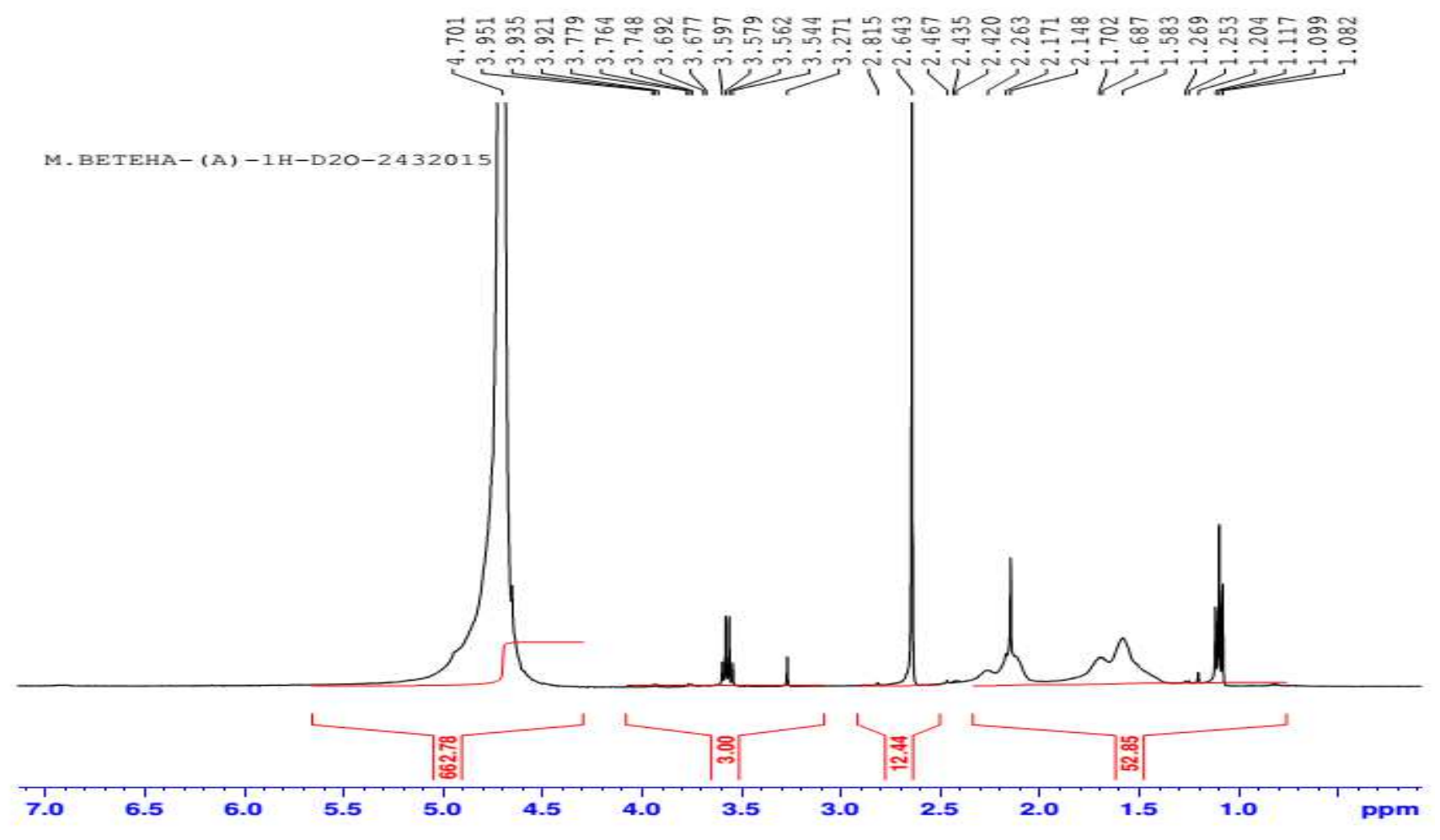

Fig. 6. Proton ${ }^{1} H-N M R$ spectra of HAPAM copolymer. 


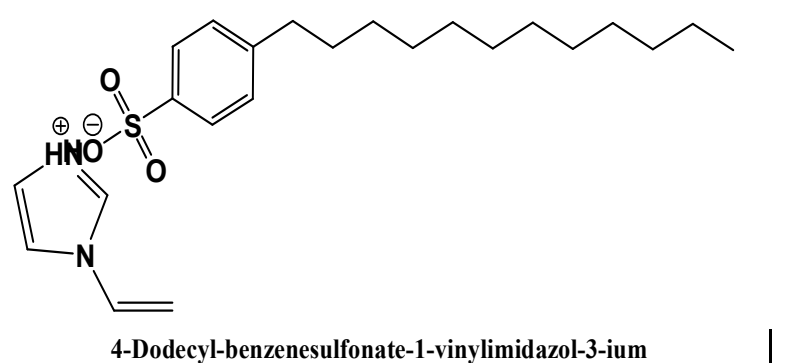

4-Dodecyl-benzenesulfonate-1-vinylimidazol-3-ium<smiles>C=CC(N)=O</smiles>

Acrylamide<smiles>C=CS(=O)(=O)C=C</smiles>

Divinyl sulfone

$\mathrm{K}_{2} \mathrm{~S}_{2} \mathrm{O}_{8} @ 60^{\circ} \mathrm{C}$

under $\mathrm{N}_{2}$ purge For12 hours

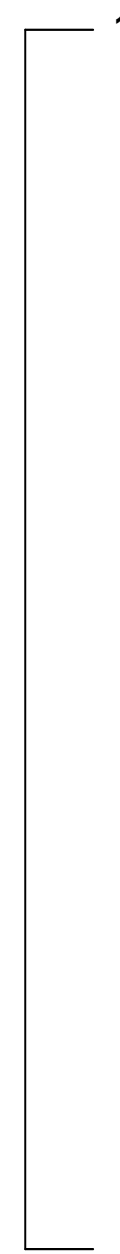

12=R<smiles>Cc1ccc(S(=O)(=O)O[Na])cc1</smiles>

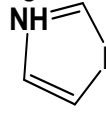<smiles>COCCO</smiles>

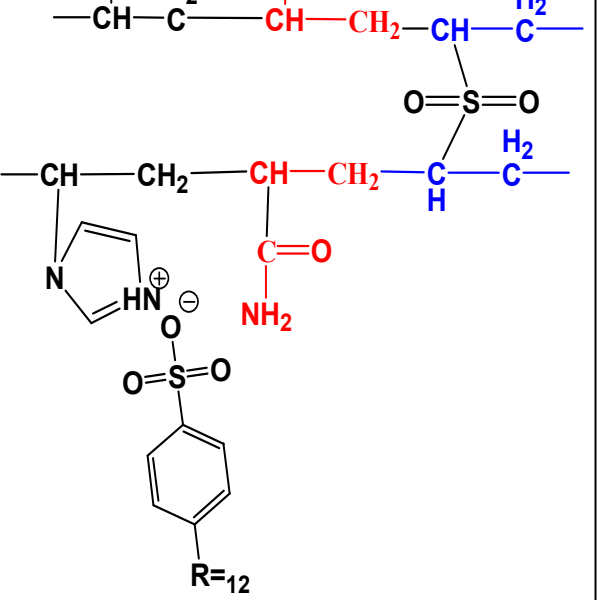

Poly(4-Dodecyl-benzenesulfonate3-[5-(butane-2-sulfonyl)-3-carbamoyl-1-methyl-heptyl]imidazol-3-ium)

Fig. 7. Chemical structure of HAPAM copolymer.

\subsection{Mechanism of Polymerization Reaction and Polymerization Kinetics}

Emulsion polymerization is initiated by the addition of initiator through micelle nucleation mechanism "heterogeneous particle nucleation" [23]. Since, used surfmer concentration exceeds its critical micelle concentration (CMC), so it tends to form clusters (micelles) which act as a meeting place for the organic (oil-soluble) monomer and the water-soluble initiator, where propagation occurs. Termination occurs after exhausting of monomer droplets leading to formation of polymer particles. These aforementioned aspects lead to propose the following possible polymerization mechanism [24]. The initial emulsion system consisted mainly of AM/DVS-swollen DBSV-n micelles, some dissolved AM, DVS and DBSV-n in the aqueous phase. Once the KPS initiator generated free radicals, they would be captured directly by AM/DVS- 
swollen micelles to initiate the copolymerization of AM, DVS and DBSV-n inside micelles. The free radicals would also react first with AM, DVS monomers and DBSV-n dissolved in the aqueous phase to form oligomeric radicals of increasing hydrophobicity although part of them may become soluble polymers in the aqueous phase because of fast chain termination before their chains are increased to sufficient length. The increasing hydrophobic nature of these oligomeric radicals would favor their entries into AM/DVSswollen micelles for further copolymerization of AM, DVS with DBSV-n to form polymer latexes.

A. Initiation

$$
\mathrm{S}_{2} \mathrm{O}_{8}^{-2} \longrightarrow 2 \overrightarrow{\mathrm{SO}}_{4}
$$

B. Propagation

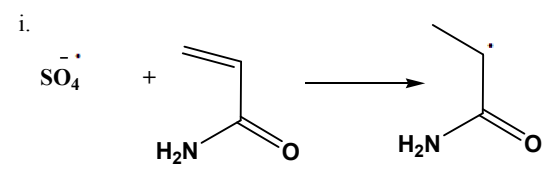

ii.

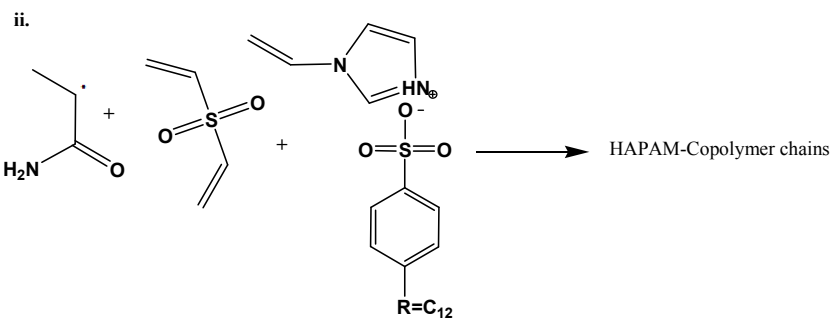

C. Termination

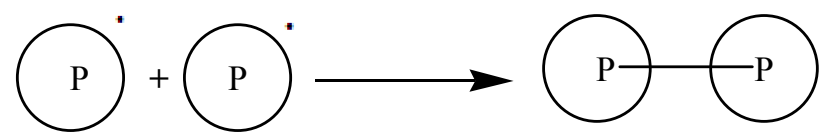

Rate of monomer conversion and polymerization kinetics were estimated through back titration and gravimetric precipitation methods, where experimental results are summarized in Table 2 and Fig. 8.

Table 2. Polymerization kinetics and conversion rate.

\begin{tabular}{ll}
\hline Time, hours & Monomer Conversion \% \\
\hline 0 & 0 \\
2 & 35 \\
4 & 63 \\
6 & 82 \\
8 & 91 \\
10 & 91.5 \\
12 & 92 \\
14 & 92.2 \\
\hline
\end{tabular}

It's obvious that, maximum conversion reach to $92 \%$ after 12 hours. As a result, optimum time of polymerization reaction through this study was adjusted at 12 hours to assure that monomer conversion occur completely.

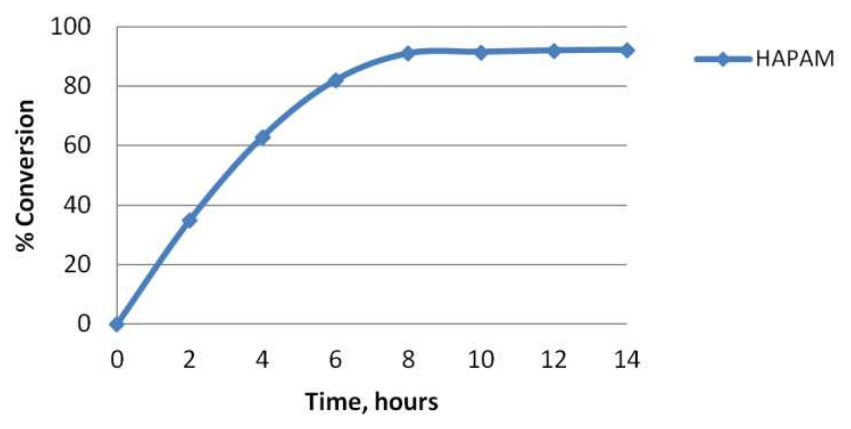

Fig. 8. Monomer conversion with time.

\subsection{Thermal Gravimetric Analysis (TGA) \& Differential Scanning Calorimetry (DSC)}

TGA-curve of the HAPAM copolymer as illustrated in Fig. 9 showed three steps for the weight loss [25]. The first one occurred in the range of $20-200^{\circ} \mathrm{C}$ (weight loss was about $14 \%$ of the total weight, corresponding to the evaporation of intra and intermolecular moisture. The second one occurred in the range of $200-300^{\circ} \mathrm{C}$ (weight loss was about $20 \%$ of the total weight, corresponding to decomposition of onium salt of imidazole and thermal decomposition of hydrophobic side chains. The third one began at $\sim 340^{\circ} \mathrm{C}$ due to decomposition of amide groups and the degradation of the polymer main chains, where weight loss was about $42 \%$ of the total weight. Beyond $450^{\circ} \mathrm{C}$, the copolymers decomposed completely where, the residual mass at $600^{\circ} \mathrm{C}$ of HAPAM was $24 \%$. Since, average reservoir temperature ranged from $90-150{ }^{\circ} \mathrm{C}$, the novel copolymer retains an average of $95 \%$ of its original structure and mass. It could be concluded that it's thermally stable under elevated reservoir temperatures.

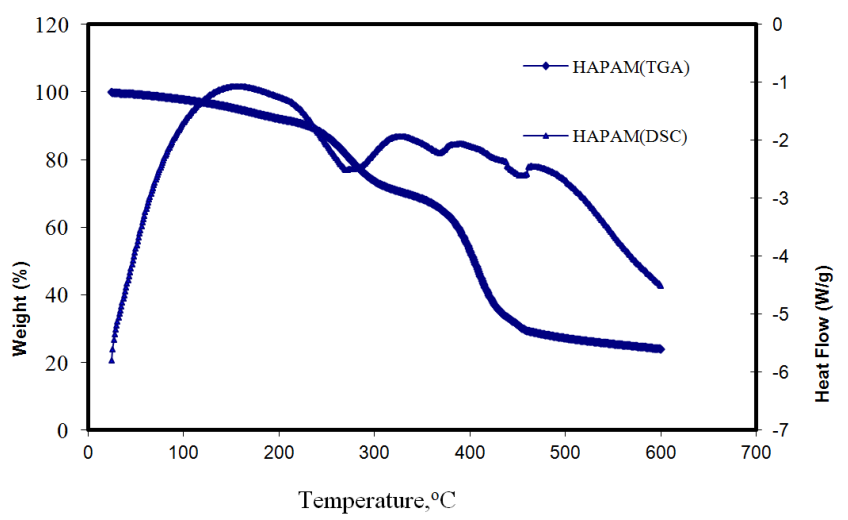

Fig. 9. TGA and DSC of HAPAM copolymer.

\subsection{Scanning Electron Microscopy (SEM) Analysis}

The HAPAM image show a more close-compacted structure as shown in Fig.10, which clearly exhibited the three-dimensional networks, was observed. This phenomenon was mostly attributed to intermolecular or intramolecular hydrophobic associations and the crosslinking reactions among the macromolecule chains [26]. Also, it is observed from the image the mesoporous structure of the 
polymer surface. Polyamides are crystalline polymers since, polar amide group leads to much larger secondary attractive forces in polyamides (due to hydrogen bonding) forming crystalline structure.
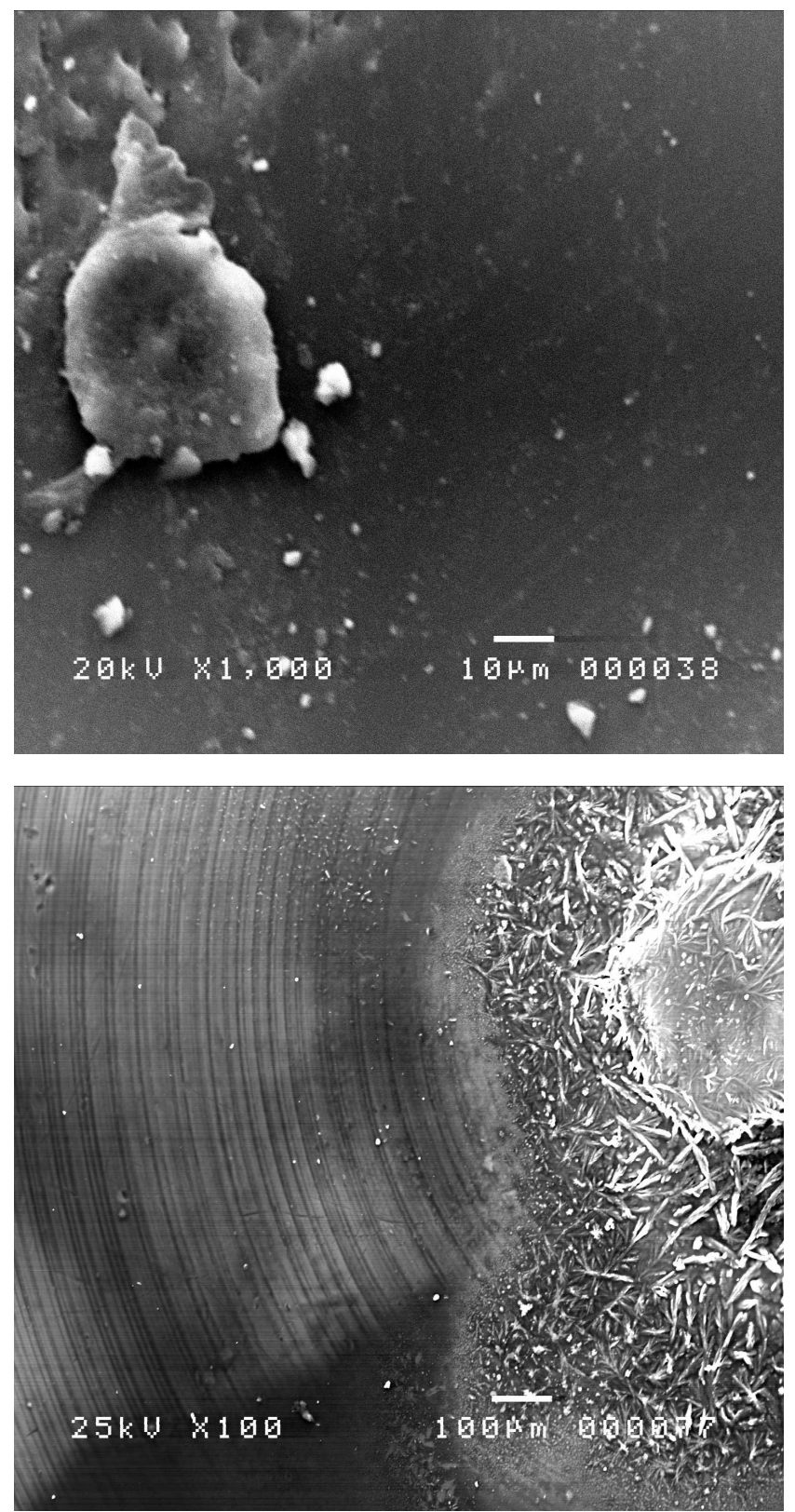

Fig. 10. SEM analysis of HAPAM copolymer.

\subsection{Transmission Electron Microscopy (TEM) Analysis}

Morphology of HAPAM copolymer was determined by HRTEM as represented in Fig. 11, which shows crosslinked nanosized particles with compact structure.

\subsection{Determination of Particle Size and Morphology}

Dynamic light scattering (DLS) technique was used in order to determine mean particle size of HAPAM latexes as in Table 3. HAPAM copolymer show some degree of particle sizes distribution ranged from 61.21-147.7 nm.
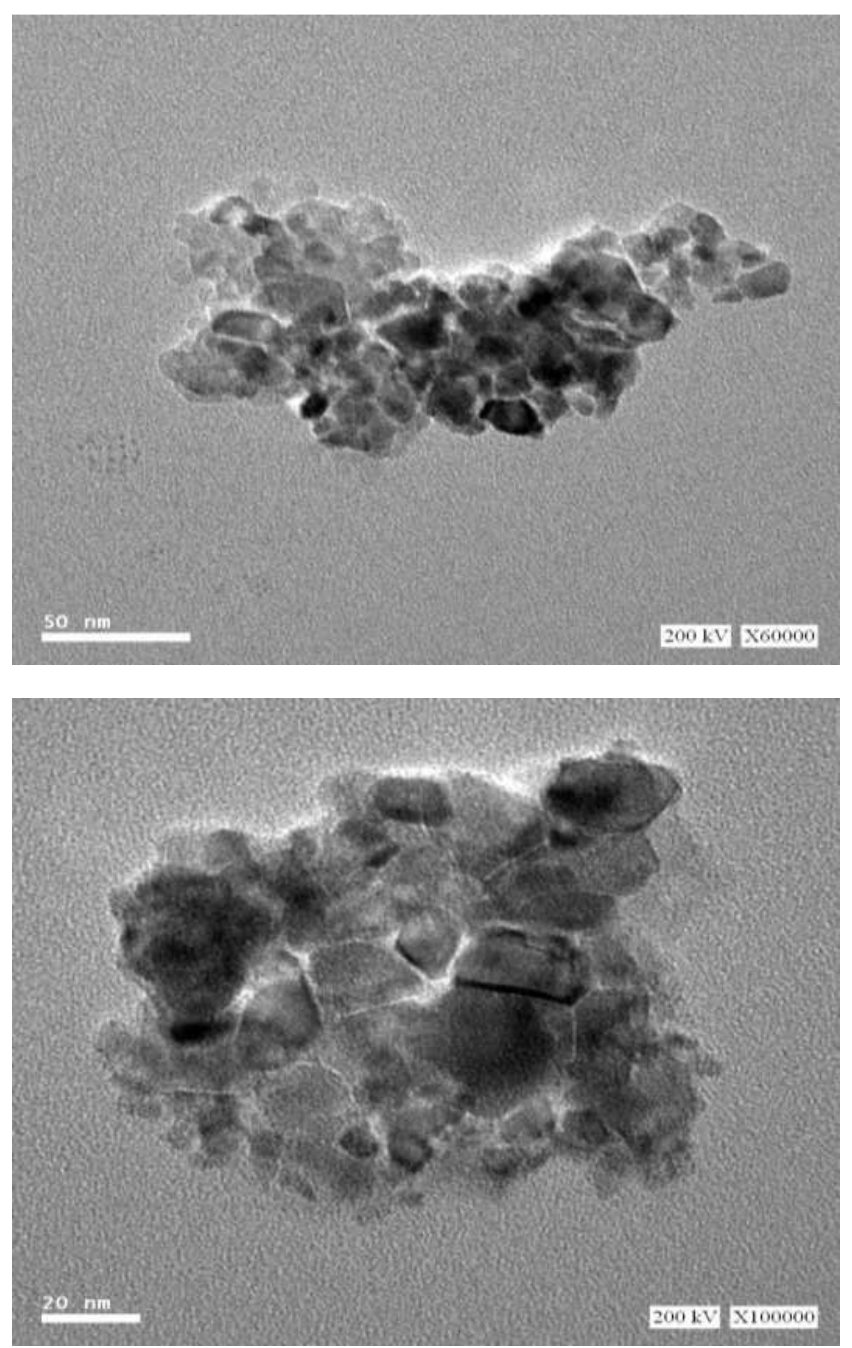

Fig. 11. TEM analysis of HAPAM copolymer.

Table 3. Particle size distribution of HAPAM copolymer.

\begin{tabular}{ll}
\hline Particle size, $\mathbf{n m}$ & Mean number\% \\
\hline 61.21 & 6.6 \\
70.89 & 21.09 \\
82.09 & 30.6 \\
95.07 & 24.8 \\
110.1 & 12.4 \\
127.5 & 3.3 \\
147.7 & 0.3 \\
\hline
\end{tabular}

Particles size distribution as well as main particle size and zeta potential of HAPAM copolymer is shown in Figs. 12-14 respectively.

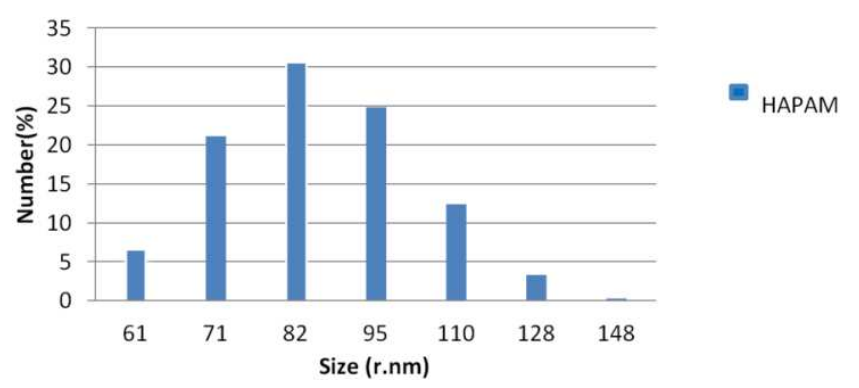

Fig. 12. Particle size distribution of HAPAM copolymer. 


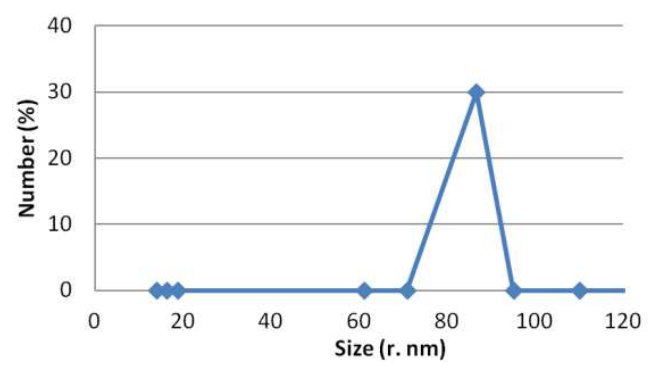

Fig. 13. Major particle size of HAPAM copolymer.

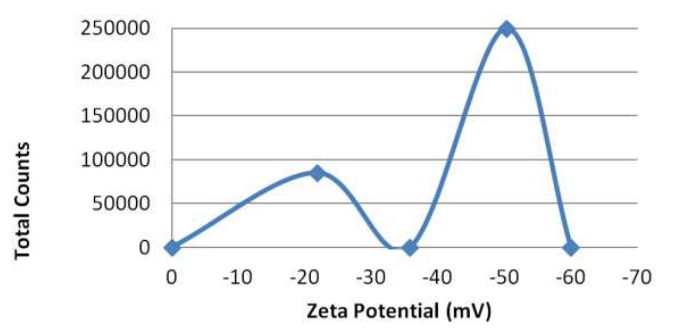

Fig. 14. Zeta potential of HAPAM copolymer.

HAPAM show main particle size of $85.35 \mathrm{~nm}$. HAPAM exhibit zeta potential values of -50.3 and $-21.8 \mathrm{mV}$ with an average value of $-46.3 \mathrm{mV}$. This indicates that it has the ability to induce wettability alteration on positively charged sandstone reservoirs during polymer flooding processes.

\subsection{Molecular Weight of HAPAM Copolymer}

The measured molecular weight through gel permeation chromatography (GPC) shows molecular weights of 1.19 $\times 10^{6} \mathrm{gmol}^{-1}$. Moreover, intrinsic viscosity or limiting viscosity number $(\eta)$ expressed as a ratio of volume over weight with units in $\mathrm{mlg}^{-1}$ is defined by equation 1 [27].

$$
\eta=\lim _{C \rightarrow 0} \frac{\mu_{s p}}{C}
$$

Where,

$$
\begin{array}{ll}
\eta & \text { Intrinsic viscosity, } \mathrm{mlg}^{-1} \\
\mu_{\mathrm{sp}}= & \text { Specific viscosity }=\left(\mu_{\text {solution }}-\mu_{\text {solvent }}\right) / \mu_{\text {solvent }} \\
\mathrm{C} & \text { Polymer concentration, } \mathrm{gL}^{-1}
\end{array}
$$

Specific viscosity $\left(\eta_{\mathrm{sp}}\right)$ expresses the incremental viscosity due to the presence of the polymer in the solution. Normalizing $\eta_{\mathrm{sp}}$ to concentration gives $\left(\eta_{\mathrm{sp}} / \mathrm{C}\right)$ which express the capacity of a polymer to cause the solution viscosity to increase (i.e. the incremental viscosity per unit concentration of polymer). As with other polymer solution properties, the solutions used for viscosity measurements will be nonideal and therefore $\eta_{\mathrm{sp}} / \mathrm{c}$ will depend on concentration (C). As with osmotic pressure, it will probably be useful to extrapolate to zero concentration. The extrapolated value of $\left(\eta_{\mathrm{sp}} / \mathrm{C}\right)$ at zero concentration is known as the intrinsic viscosity $(\eta)$. The copolymer molecular weight was expressed relatively with the intrinsic viscosities [28]. Equation 2 was used to calculate the molecular weight of copolymer [29], where the experimental results are summarized in Table 4 and Fig. 15

$$
\eta=0.719 * 10^{-2}(M w)^{0.77}
$$

\begin{tabular}{|c|c|c|c|c|}
\hline $\mathbf{C} \mathbf{g L}^{-1}$ & $\eta_{\text {sp }}$ & $\eta_{\mathrm{sp}} / \mathbf{C}$ & $\eta \mathbf{L g}^{-1}$ & Molecular Weight $\times 10^{6} \mathrm{gmol}^{-1}$ \\
\hline 0.01 & 3.9 & 387.3 & & \\
\hline 0.02 & 8.4 & 422.3 & & \\
\hline 0.04 & 19.7 & 492.2 & 352.3 & 1.19 \\
\hline 0.08 & 50.6 & 632.0 & & \\
\hline
\end{tabular}

Table 4. Intrinsic viscosity, calculated and measured molecular weight of HAPAM copolymer.
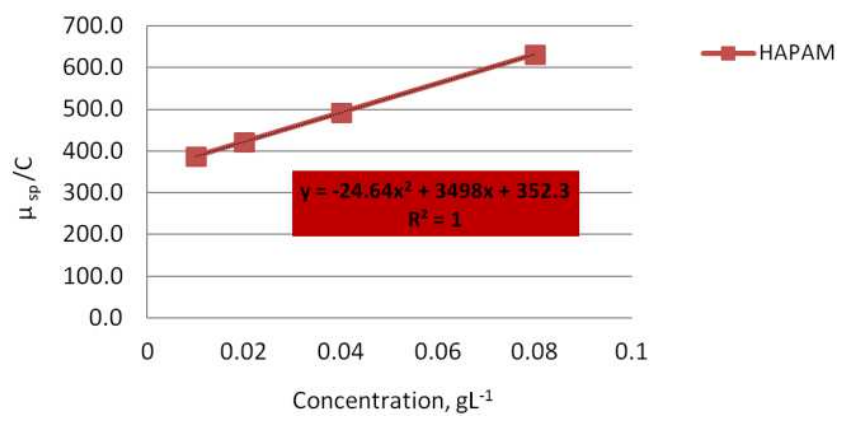

Fig. 15. Intrinsic viscosity of HAPAM copolymer.

The GPC method shows molecular weights of $1.19 \times 10^{6}$ gmol $^{-1}$ which are closer to values calculated with intrinsic viscosity method, $1.23 \times 10^{6} \mathrm{gmol}^{-1}$.

\section{Evaluation of Sandstone Rock Wettability}

\subsection{Quantitative Assessment}

Wettability was evaluated by measuring contact angle between oil droplet and rock surface at simulated reservoir conditions (Temperature $=90^{\circ} \mathrm{C}$ and salinity $=40,000 \mathrm{ppm}$ ) and polymer concentration of $2 \mathrm{~g} \mathrm{~L}^{-1}$. The contact angles measured at different stages of the wettability experiment for a spherical sandstone core plate. Fig. 16 shows the images of the drop attached to the plate for a period of two days. After aging with crude oil for a day at elevated temperature, the plate found to be oil-wet. The plate is then immersed in copolymer-brine solution at reservoir conditions, where oil droplet hanged on the plate lower surface and photographed for 48 hours. Images are analyzed to calculate contact angle. It's observed that advancing contact angle decreases with time and stabilizes at a value of about $74^{\circ}$.

Wettability alteration by polymer addition can be explained on basis of;

a) By adsorption of polymer molecules on the rock surface, physicochemical properties altered, where thin wetting water film becomes unstable at the interface [5] and ruptured so, creating a continuous oil path for oil displacement which in turn increases oil recovery.

b) Silica surfaces (sandstone rock) are negatively charged above $(\mathrm{PH}=2)$ so, positively charged nitrogen bases can adsorb on rock surface and alter wettability from oilwet to water-wet. This is confirmed by reducing of 
contact angle to nearly $74^{\circ}$.

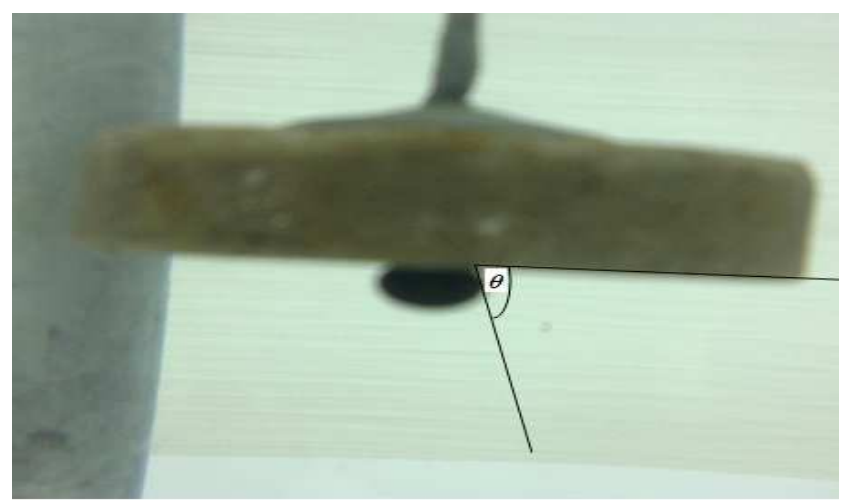

Figure 16. Contact angle photograph after 48 hours.

\subsection{Qualitative Assessment}

Fig. 17 shows qualitative assessment of wettability carried out through Two-phase separation test, it's observed that grinded sandstone grains are dispersed in oil phase in case of oil and brine solution as shown in Figure (17A). This indicates that sandstone is oil-wet. While, in case of HAPAM Figure (17B), the sandstone grains sink into aqueous phase of polymer solution. This indicates that sandstone grains become water-wet.

All of the aforementioned results confirm the ability of HAPAM copolymer to alter wettability of the rock from oilwet to water-wet which in turn increases oil recovery through enhancing displacement efficiency.

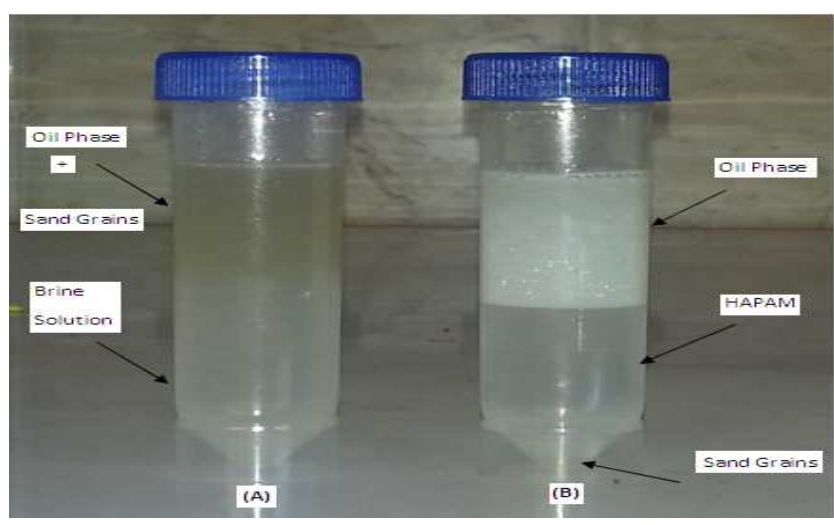

Fig. 17. Two-phase separation test.

\section{Conclusion}

A novel high molecular weight hydrophobically associated polyacrylamide copolymer was successfully synthesized by free radical emulsion polymerization reactions using amphoteric polymeric surfactant and a hydrophobic moiety which anchored on acrylamide backbone structure so increase latex stability and enhancing its properties. Chemical structures of the prepared surfmer and HAPAM copolymer were characterized by different spectroscopic techniques. Their thermal stabilities were justified by TGA analysis which shows initial mass loss of copolymer at $270.52^{\circ} \mathrm{C}$, so it is considered as promised EOR candidate due to its high thermal stability at severe reservoirs temperature. The prepared latex has nanosized structure, so it's favorable for porous sandstone flooding. Its molecular weight was measured by GPC and calculated from intrinsic viscosity, they show high molecular weight values of $1.19 \times 10^{6} \mathrm{gmol}^{-1}$. Finally, its ability for wettability alteration was evaluated in relevant to sandstone reservoirs and shows a promised results to alter oil-wet rock to water-wet, so increase recovered oil amount.

To the best of our knowledge, no previously reported HAPAM copolymer for wettability alteration, so this polymer is highly recommended for enhanced oil recovery applications in high pressure-high temperature offshore sandstone reservoirs. A study of rheological and solution properties of the prepared copolymer is ongoing research point.

\section{Acknowledgments}

The authors wish to thank the Science \& Technology Development Fund (STDF) of Egypt for financial support.

\section{References}

[1] Tabary R, and Bazin B, "Advances in chemical flooding” IFPOAPEC Joint Seminar; Improved Oil recovery (IOR) Techniques and Their Role in Boosting the Recovery Factor, France (2007).

[2] Aldasani A, "Updated EOR screening criteria and modeling the impacts of water salinity changes on oil recovery" $\mathrm{PhD}$. thesis Presented to the Faculty of the Graduate School of the Missouri University of Science and Technology (2012).

[3] Nguyen P T, Do B P H, Pham D K, Nguyen H A, Dao D Q P and Nguyen B D, SPE 92667, 2012, 436-445.

[4] Al-Hadhrami H S, SPE 71866 Reservoir Evaluation and Engineering, 2001, 4, 179- 186.

[5] Subhash C, Ayirala, Chandra S Vijapurapu, Dandina N. Rao, Journal of Petroleum Science and Engineering, 2006, 52, 261274.

[6] Goddard III W A, Wu Y, Shuler PJ ,Blanco M, and Tang Y, SPE Journal, 2008,13, 26-34.

[7] Bastiat G, Grassl B, and François J, Polym. Int., 2002, 51, 958-965.

[8] Feng Y J, Billon L, Grassl B, Bastiat G, Borisov O and François J, Polymer, 2005, 46, 9283-9295.

[9] Zhao Y Z, Zhou J Z, Xu X H, Liu W B, Zhang J Y, Fan M H and Wang J B, Colloid Polym. Sci., 2009, 287, 237 -241.

[10] Jiang T T , Lu J, Wang H Y, Wang B H, Han H J , Wu H J , Advanced Materials Research, 2013, 805-806, 1344-1347.

[11] Shashkina A. Y, Zaroslov D Yu, Smirnov V A, Philippova O E, Khokhlov A R, Pryakhina T A, and Churochkina N A, Polymer, 2003, 44, 2289- 2293. 
[12] Camail M, Margaillan A, Martin I, Papailhou A L and Vernet J L, Eur. Polym. J., 2000, 36, 1853 -1863.

[13] Gao B J, Guo H P, Wang J, and Zhang Y, Macromolecules, 2008, 41, 2890- 2897.

[14] Philippe Reb, Kristina Margarit-Puri, Markus Klapper, and Klaus Müllen, Macromolecules, 2000, 33, 7718- 7723.

[15] Guyot A, Adv. Colloid Interface Sci., 2004, 108 -109, 3-22.

[16] Léger A, Weber L and Mortensen A, Acta Materialia, 2015, 91, 57- 69 .

[17] Das S , Thundat T and Mitra S K , Colloids and Surfaces A: Physicochemical and Engineering Aspects, 2014, 446, 23-32.

[18] Arsalan N , Buiting J J , and Nguyen Q P , Colloids and Surfaces A: Physicochemical and Engineering Aspects, 2015, 467, 107-112.

[19] Jiang G, Ren Y, Zheng D, Sun S, An Y and Wang C, Petroleum Exploration and Development, 2015, 42, 125- 128.

[20] Wu Y M, Chen Q F, Xu J and Bi J M, Journal of Applied Polymer Science, 2008, 108, 134 -139.
[21] Xu J, Zhao W P, Wang C X and Wu Y M, Express Polymer Letters, 2010, 4, 275-283.

[22] Al-Sabagh A M, Kandile N G, El-Ghazawy R A, Noor El-Din M R, and El-sharaky E A, Egyptian Journal of Petroleum, 2013, 22, 531- 538 .

[23] Monégier du Sorbier Q, Aimable A and Pagnoux C , Journal of Colloid and Interface Science, 2015, 448, 306 -314.

[24] Xu X J, and Chen F, Polymer, 2004, 45, 4801- 4810.

[25] Samaneh Saber-Samandari, Mustafa Gazi,, Journal of the Taiwan Institute of Chemical Engineers, In Press, 2015, doi:10.1016/j.jtice.2015.01.013.

[26] Gou S, Ye Z, Feng M, Liu M, Huang Z, and Liu T, J. Appl. Polym. Sci., 2013, 130, 2901-2911.

[27] $\mathrm{Xu} \mathrm{J,} \mathrm{Wu} \mathrm{Y,} \mathrm{Wang} \mathrm{C,} \mathrm{and} \mathrm{Wang} \mathrm{Y,} \mathrm{Journal} \mathrm{of} \mathrm{Polymer}$ Research, 2009, 16, 569- 575.

[28] Li J, Wu F P, and Wang E J, Chinese Journal of Polymer Science, 2010, 28, 137-145.

[29] Klein J and Conrad K D, Makromolecule Chemistry \&Physics, $1980,181,227-240$. 